\title{
Challenges and Reforms in Midwifery and Nursing Regulatory Systems in India: Implications for Education and Practice
}

Kaveri Mayra ( $\square$ kmayra86@gmail.com )

University of Southampton https://orcid.org/0000-0001-8395-0738

Sabu Padmadas

University of Southampton

Zoë Matthews

University of Southampton

\section{Research}

Keywords: Nursing, midwifery, education, practice, regulation

Posted Date: August 17th, 2020

DOI: https://doi.org/10.21203/rs.3.rs-56709/v1

License: @ (i) This work is licensed under a Creative Commons Attribution 4.0 International License. Read Full License 


\section{Abstract}

Background: Quality of maternal healthcare is determined by the strength of the regulatory framework in which health workers practice. Nursing regulation is poor and midwifery coexists with nursing in India, where $88 \%$ of midwifery and nursing education is provided by the private sector. The Indian health system faces major challenges for maternal health provision, with a $12 \%$ share of total maternal deaths globally, poor quality, indeterminate regulatory functions and lack of reforms.

Methods: We undertake a qualitative investigation to understand the experiences and perceptions of nurse-midwife leaders on midwifery and nursing regulatory systems in India and further examine their influence on midwifery education and development. Thirty-four in-depth interviews were conducted with senior midwifery and nursing leaders representing administration, advocacy, education, regulation, research and service provision.

Results: Our findings shows a lack of importance accorded to midwifery roles within the nursing system. The councils and statutes do not adequately reflect midwifery practice, and hence they are a barrier to good quality care provision. The lack of amendment of Acts and lack of representation of midwives and nurses in key governance positions in councils and committees have restrained or undermined leadership positions, which in turn has also impaired the growth of the profession. The regulatory framework standards for midwifery and nursing education in private institutions appeared imprudent with lack of opportunities for practice and unfair assessment practices. Discrimination against midwifery and nursing students was rampant in the education system in public and private institutions, with limited opportunities for clinical practice when compared to medical students.

Conclusions: The study concludes with a reform measure including a recommendation for implementing direct-entry midwifery education, empowering midwives and nurses with autonomy, decision-making powers within health care and workforce governance.

\section{Background}

Midwives and nurses are integral to health care provision in India. A comprehensive and strong regulatory mechanism is therefore needed to regulate education, practice and to ensure competent nurses and midwives in the Indian health workforce. The International Confederation of Midwives (ICM) recommends six functions that regulatory bodies should maintain; setting the scope of practice, pre-registration of education, registration, relicensing and continuing competence, complaints and discipline, code of conduct and ethics ${ }^{[1]}$. The Indian Nursing Council (INC) and State Nursing Councils (SNC) play key roles in the regulation of nursing and midwifery education in India. They oversee registration, licensing, inspection and examination. However, there is duplication of these roles both at the national and the state levels ${ }^{[2]}$. The course curriculum is centrally designed and approved by the INC.

In India, nurse-midwives become part of the health care workforce after completing 2-4 years of mandatory Pre Service Education (PSE) which aims to provide skill sets of both professions. Currently, India does not have a cadre of competent independent midwives. Midwifery education is provided both as a part of a diploma course called General Nursing and Midwifery (GNM) for three years and also as a part of a four year BSc nursing degree. The midwifery component in BSc nursing degree lasts approximately six months when compared to 18 months midwifery education after completing three years of a nursing degree in other countries ${ }^{[3]}$. There are also elements of midwifery skills education in the Auxiliary Nursing and Midwifery (ANM) certificate course. The curriculum of these three entry level courses of midwifery education are not comparable with the ICM recommended skill-set ${ }^{[1]}$. The National Health Mission (NHM) of the Government of India (GOI) recently initiated efforts to formulate clear operational guidelines to implement midwifery training in India ${ }^{[4]}$. An existing diploma course for Nurse Practitioners in Midwifery (NPM) has been updated for this purpose. It is essential to understand India's midwifery education, regulation and practice capacities as there is evidence suggesting that $87 \%$ of maternal health care during childbirth can be managed effectively by professional midwives ${ }^{[5]}$.

Midwives and nurses are recognized as key human resources for quality health care provision, yet they are often neglected and subjected to discrimination right from their PSE to all through their professional careers ${ }^{[6,7]}$. Indian nursing and midwifery education is faced with several challenges including resource constraints such as lack of teachers; a mismatch between theory and practice in learning; a lack of opportunities for practice; discrimination and stigma ${ }^{[2,8-10]}$. Around $88 \%$ of nursing education in India is provided by the private sector where the quality of education is reportedly poorer than in public institutions, especially in large and resourcepoor states in northern India ${ }^{[6]}$. The private share in nursing education has continued to grow in terms of the number of training institutions and recruitment quota, in response to the global demand of nurse-midwives making India rank second in terms of nurses 
outmigration ${ }^{[11]}$. The uneven distribution of nursing institutes is yet another challenge. The privatization of education has led to a skewed production of human resources for health (HRH) with six high HRH producing states of Andhra Pradesh, Karnataka, Kerala, Maharashtra, Pondicherry and Tamil Nadu, which represents $31 \%$ of the Indian population but have $63 \%$ of nursing and $58 \%$ of medical colleges compared to the eight low HRH producing states of Bihar, Chhattisgarh, Jharkhand, Madhya Pradesh, Uttar Pradesh, Uttaranchal, Odisha and Rajasthan, which share $46 \%$ of the population but only $20 \%$ of nursing and $21 \%$ of medical colleges ${ }^{[6,12]}$. The training institutes are further skewed toward the urban areas within these states ${ }^{[6]}$. Regulatory mechanisms are reportedly relaxed to allow training in certain private institutes, despite capacity challenges ${ }^{[7]}$.

The current midwifery and nursing regulatory structure of India also faces many challenges. It is dominated by medical representatives and provides little authority to nursing and midwifery regulators. The regulation of nurses and midwives' migration is cumbersome; the regulation of practice is weak, and there is a failure to improve the quality of education in private sectors ${ }^{[6,13-18]}$. Over the last few years, non government and international development organizations have coordinated efforts to improve preservice and in-service education in India ${ }^{[18-19]}$. However, these efforts have not been extended to sustaining a strong regulatory structure. There have been some initiatives to understand the quality of nursing and midwifery education and services in India but little attention is given to addressing the challenges in regulation ${ }^{[6,10,16]}$.

\section{Methods}

Our study investigates the regulatory system to understand its potential impact on nursing and midwifery education and development in India. The objectives of this research are threefold: (i) to document the regulatory system for nursing and midwifery in India and highlight its weaknesses; (ii) to understand the underlying gender and power based issues adding to the regulatory challenges of midwifery and nursing and (iii) to recommend reforms measures for strengthening nursing and midwifery regulation and workforce governance in India.

We use qualitative methods to examine the perceptions and experiences of nurse-midwives in senior leadership roles regarding the regulatory systems of midwifery and nursing in India. The study participants were selected through purposive snowball sampling in five states in India: Rajasthan, Odisha, Bihar, Madhya Pradesh and West Bengal and at the national level. The five states selected represent different cultural, social, economic and health contexts. All selected states, except West Bengal, are amongst the low HRH producing states, known for poor quality of midwifery and nursing education and face similar challenges. West Bengal is known for good nursing and midwifery governance and quality of education, especially in the public sector. The selection of leaders at the national level allows us to understand the larger context of health policy making and governance in India. The inclusion criteria for in depth interviews followed a strategy to select nursing and midwifery leaders who represent various domains of administration, advocacy, education, regulation and service provision. Some of the participants represented more than one of the domains. The paper presents a global perspective from leaders representing nursing and midwifery governance based in the United Kingdom and Switzerland. Switzerland is the hub of all the international development organizations including the World Health Organisation (WHO), that plays a key role in global nursing and midwifery governance. United Kingdom (UK) reflect and learn from a successful model of midwifery education and regulation. Additionally, the study includes a review of the nursing acts from all the selected states and the INC act to understand the guiding documents for regulation in India. The interviews with participants from UK and Switzerland were mainly focussed on the regulation of midwifery.

\subsection{Data collection and analysis}

In-depth interviews were conducted between July 2018 and January 2019. The participants were informed about the purpose of the study over email or phone before seeking appointment for interviews. Forty three leaders were approached for data collection. Nine of them could not provide time for the interview or dropped out. All the interviews were conducted in person, except three which were done as a video call. The study instrument is a semi-structured guide with three sections: 1 ) background information; 2) participant's role and responsibilities and 3) nursing and midwifery regulation in India.

The interviews were conducted by the lead author, an experienced qualitative researcher with educational background in nursing, midwifery and with research experience on issues pertaining to nursing and midwifery in India. All participants were aware of the researcher's background, professional qualifications and the rationale of the study prior to the interviews. The interviews were carried 
out in English in most cases, or in Hindi and Bengali in a few states. The female lead researcher is fluent in these languages. Data were processed and analysed thematically using NVivo 12 software. Coding was applied simultaneously with data collection which helped to clarify emerging themes in subsequent interviews. The codebook consisted of apriori codes which were supplemented by deductive codes, as the analyses progressed.

\subsection{Participant profile}

The age of respondents varied from 46 to 83 years. All respondents were midwives and nurses except one who did not receive formal education in midwifery. Twenty-six participants completed their education in nursing and midwifery in India. Their qualification was the degree that combined nursing and midwifery curricula. Four out of the 34 participants were men, who were all interviewed in Rajasthan, where men are allowed to opt for midwifery and nursing education. All respondents held senior level positions. Two of them have retired from service. The total experience of the participants ranged between 24 to 60 years. Table 1 presents relevant demographic, qualifications and work profile related information of the participants.

Table 1: Participant profile

\begin{tabular}{|lll|}
\hline Indicator & No. of participants/ Range & Total responses (N) \\
\hline Age Range & & 30 \\
\hline $40-60$ years & 18 & 30 \\
\hline $61-80$ years & 11 & 30 \\
\hline$>80$ years & 1 & \\
\hline Gender & & 34 \\
\hline Female & 30 & 34 \\
\hline Male & 4 & \\
\hline Qualification & & 33 \\
\hline RN , RM & 32 & 33 \\
\hline RM & 1 & 33 \\
\hline MSc Nursing and MPH & 22 & 33 \\
\hline PhD & 11 & 17 \\
\hline Experience (years) & & 17 \\
\hline Urban Experience Range & $5-46$ & 29 \\
\hline Rural Experience Range & $0-25$ & $17-60$ \\
\hline Total Experience Range & & \\
\hline
\end{tabular}

\section{Results}

The interviews focused on the quality of nursing and midwifery education, regulation, challenges of regulation in both education and practice, and recommendations to improve regulation of nursing and midwifery education and service provision. The findings are presented in four sections: 1) regulatory system for midwifery and nursing; 2) weaknesses in the current regulatory system; 3 ) gender and power as factors influencing regulation; and 4) midwifery under nursing as a regulatory challenge, in India.

\subsection{Regulatory system of midwifery and nursing}

This section presents a review of the regulatory acts implemented in the selected states and national level (Table 2). All the acts are extracted from the respective council's websites. 
Table 2: Nursing and midwifery Acts reviewed, by year of enactment

\begin{tabular}{|l|c|}
\hline Name of the Act & Year of enactment \\
\hline The Indian Nursing Council Act ${ }^{[20]}$ & 1947 \\
\hline The Bengal Nurses Act ${ }^{[21]}$ & 1934 \\
\hline The Bihar and Orissa Nurses Registration Act ${ }^{[22]}$ & 1935 \\
\hline The Central provinces Nurses Registration Act (Madhya Pradesh) ${ }^{[23]}$ & 1936 \\
\hline The Orissa Nurses and Midwives Registration Act ${ }^{[24]}$ & 1964 \\
\hline Rajasthan Nurses, Midwives, Health visitors and Auxiliary Nurse Midwives Registration Act ${ }^{[25]}$ & \\
\hline
\end{tabular}

On review it was found that some state acts are older than the INC act of 1947. All the state acts are similar in content which includes the profile of members, key definitions, process of becoming a member, information for professional registration, reregistration and clauses under which a practitioner can lose registration. The profile of the governing body is not uniform, ranging from seven members in Odisha to fifteen in Bihar. Every council has a set number of members who are doctors and some members non-nursing/ midwifery administrators. The ex-officio members, four to seven in every council, can be elected multiple times as long as they hold the position by virtue of which they have been elected. There is no system of direct application unless through nomination, followed by election. None of these Acts have been amended since they were introduced way back in the 1930's and 40 's. Bihar shared a council with Odisha at the time of its creation (in 1935) but did not amend the Act even though soon after its creation Odisha started a separate council (1938).

The language of the Acts is not gender sensitive and all the Acts refer to the registrar as 'he' or 'his' even though historically the position of registrar in most nursing councils is held by women, including in the current circumstances where four out of five SNC's registrars interviewed in this study are women. The curriculum is not part of the act. It is centrally designed and implemented with some variation in the states.

The content varies a little for some Acts. The Rajasthan Nurses, Midwives, Health visitors and Auxiliary Nurse Midwives Act of 1964 is the most detailed Act entrusting the power of council through eight activities, including grounds on which the state government has the right to dissolve the Council and the Act. The language of the RNC Act is comparatively gender sensitive. The Odisha ad Rajasthan's Act and Council include 'midwives' in the title. None of the other Acts mention anything in favour or against independent midwifery practice. Odisha is the only state that registers dai's (traditional birth attendants) and has badges made for every category of registrant, although it is not mandatory to wear. The Central provinces Nurses Registration Acts of 1936, in Madhya Pradesh discourages private practice even though it does not mention what it means for nurses working in the private health care provision and education.

All six Acts regulate education and none of them mention regulating practice or maintaining and updating the knowledge and skills of practicing professionals. There are no separate Acts at the state or central level that regulates nursing and midwifery practice. The Acts also do not mention the INC's role in supervising the SNCs. This could be because the state Acts, except Rajasthan, were formed before the INC Act of 1947 - although Rajasthan's Act also does not mention INC's role. At the national level, the key activities are maintenance of registers for all nursing and midwifery courses, registration at the national level, licencing of nursing training institutes, setting the curriculum for every course and maintaining uniformity. The INC website has information on the National Registration Tracking System (NRTS), which was recently launched to maintain a database of nurse-midwives in the country from every state, to enable tracking and regulate placement. As of August $9^{\text {th }} 2020$, there are $9,90,524$ professionals enrolled under NRTS (INC, 2020).

The council Acts do not provide any guidance on nurses' domestic or overseas migration clarifying the terms of registration while serving in a foreign country, practice in India on return; higher education in nursing and midwifery or other health-related education in other countries. 


\subsection{Structure and functioning of midwifery and nursing regulation}

\section{- Weaknesses in the regulatory and governing bodies}

The INC is the main body that regulates nursing and midwifery education in India. The SNCs manage regulation at the state level. Regulation of nursing and midwifery education covers certificate, diploma and degree courses in public and private sector. Every council has positions of President and Registrar as the key administrators. Routine administration is in the purview of the Registrar. One participant from the national level objected to the processes and terms of references of administrators at the councils.

"These days in nursing council a person can be President for life! The council seems to be happy with it... elections are conducted in every term but the leadership does not change. They can change that if they want to." (National)

"INC president has been in position for 15 years... One term of leadership at INC is 4 years."(National)

Most council participants mentioned a lack of human resources as a key challenge to managing the councils work such as admission, examination, inspection, registration and re-registration in each state. The role of the INC is different from the SNCs. The INC sets the national curriculum, oversees registration, implements the NRTS and conducts inspections in all the states. Some of these services overlap, such as institutional inspections which are carried out both by the SNCs and the INC independently when starting and maintaining a new institution. The reason for this was not clearly explained by the participants. One respondent from Rajasthan commented that this duplication of activity was unnecessary and should be handled solely by the respective SNCs.

Workload challenges were repeatedly mentioned particularly as the number of training institutes expand rapidly. Table 3 shows the number of nursing and midwifery educational institutes in each study state (along with seats) and total institutions in India. Between 2005 to 2018, the total ANMTCs increased from 254 to 1564, the total GNMTCs to 979 to 2812 and the total colleges of nursing from 349 to 1761 . Bihar has the lowest number of institutes and admission capacity in comparison to the rest, while Madhya Pradesh has the highest. Bihar has $8.6 \%$ of India's population but only $0.5 \%$ of total BSc Nursing institutes. The capacity of bachelors degree in nursing education has increased four times and post graduation in nursing by eleven times in India between 2005 and 2018. This increase has been disproportionate. The number of institutes providing GNM education increased from 22 to 324 in Madhya Pradesh but remained low in Bihar (13 to 21) between 2005 to 2018. The range of 991 to 12,970 GNM places for admission is disproportionately high especially given that the population coverage is highest in Bihar followed by West Bengal, Madhya Pradesh, Rajasthan and Odisha. Bihar does not provide any higher education prospects for its graduating nurse-midwives in the state. Each of the states have between 20-100 seats for GNM and BSc Nursing per institute. Within the states, the number of training institutions are not proportionate with the state's population. There are no data available from the INC that disaggregates the distribution of institutes and admission capacity by public and private sector.

Table 3: Nursing and midwifery training institutions in selected states (2018) 


\begin{tabular}{|c|c|c|c|c|c|c|}
\hline State & Year & $\begin{array}{l}\text { BSc } \\
\text { Nursing }\end{array}$ & $\begin{array}{l}\text { MSc } \\
\text { Nursing }\end{array}$ & $\begin{array}{l}\text { General Nursing and } \\
\text { Midwifery }\end{array}$ & $\begin{array}{l}\text { Auxiliary Nursing and } \\
\text { Midwifery }\end{array}$ & $\begin{array}{l}\text { Population (2011 } \\
\text { Census) }\end{array}$ \\
\hline \multirow[t]{3}{*}{ Bihar } & 2018 & 9 & 0 & 21 & 90 & \multirow[t]{3}{*}{$10,38,04,637$} \\
\hline & 2011 & 0 & 0 & 11 & 29 & \\
\hline & 2005 & 0 & 0 & 13 & 25 & \\
\hline \multirow{3}{*}{$\begin{array}{l}\text { Madhya } \\
\text { Pradesh }\end{array}$} & 2018 & 140 & 50 & 324 & 71 & \multirow[t]{3}{*}{$7,25,97,565$} \\
\hline & 2011 & 101 & 29 & 135 & 82 & \\
\hline & 2005 & 19 & 2 & 22 & 9 & \\
\hline \multirow[t]{3}{*}{ Rajasthan } & 2018 & 169 & 26 & 164 & 12 & \multirow[t]{3}{*}{$6,86,21,012$} \\
\hline & 2011 & 149 & 5 & 176 & 11 & \\
\hline & 2005 & 3 & 0 & 57 & 8 & \\
\hline \multirow[t]{3}{*}{ Odisha } & 2018 & 29 & 11 & 78 & 127 & \multirow[t]{3}{*}{$4,19,47,358$} \\
\hline & 2011 & 16 & 5 & 48 & 67 & \\
\hline & 2005 & 4 & 0 & 10 & 16 & \\
\hline \multirow[t]{3}{*}{ West Bengal } & 2018 & 23 & 12 & 72 & 6 & \multirow[t]{3}{*}{$9,13,47,736$} \\
\hline & 2011 & 16 & 7 & 49 & 59 & \\
\hline & 2005 & 2 & 2 & 28 & 20 & \\
\hline \multirow[t]{3}{*}{ All India } & 2018 & 1,761 & 590 & 2,812 & 1,564 & \multirow[t]{3}{*}{$1,21,08,54,977$} \\
\hline & 2011 & 1,570 & 450 & 2,351 & 935 & \\
\hline & 2005 & 349 & 54 & 979 & 254 & \\
\hline
\end{tabular}

\section{Sources: Indian Nursing Council Website, Census 2011}

The regulatory challenges in education are different in public and the private institutions. Although the curriculum being taught is uniform in every state, the respondents argued that quality of education is not the same in the public and private sector. Respondents from every state shared that regulation of education was comparatively poorer in private sector institutions.

"Practical experience (for students) is zero in private sector" (Bihar)

"Private sector regulation is poor. No one sees that." (Bihar)

Health facilities have affiliations to medicine and nursing training institutes, both from public and private. It is difficult for the hospital authority/ staff to ensure that every student receives required amount of practice as recommended for successful course completion. A respondent from Bihar shared from her experience of working in a government tertiary level teaching hospital.

"Head of the Department (doctor) says my medical students will practice first (in the labour room). The nursing (and midwifery) students observe cases but can only request to give them a chance to practice. $100 \%$ cases (births) are conducted by medicine students... thecouncil inspected, yet did nothing to change this." (Bihar)

Such issues were shared from every state except West Bengal. The most common challenge mentioned was private institute students not getting an opportunity for practical experience during pre-service education. Students often filled up their case books with fabricated cases as a way to pass the course. This practice goes unchecked, though well acknowledged. Even more alarming is the illegal procurement of fake certificates by untrained persons. This was mentioned by representatives of council and others. To 
address this problem, the councils take precautions before registering candidates from other states. However, the Registrars do not have sufficient resources to tackle such challenges which represents a major barrier in councils' functioning.

The lack of practical exposure for students in private institutes leads to a lack of knowledge and skills in comparison to those from government-led institutes. This challenge is acknowledged in private hospitals. Most private hospitals have their own education institutes but reportedly they do not have confidence in their own students because of their lack of skills. A participant from Rajasthan reflected on the poor training quality of students from private institutes and acknowledged that the state council is aware of the problem.

"The (state) council knows about it and does nothing" (Rajasthan)

The participant further shared that students sometimes pay bribes to the professors after practical examination or even inside their answer sheets during examination for theory papers to score well when the scorer finds the bribe inside it. Many teachers succumb to this practice, but not all surrender to the pressure as mentioned by a participant.

"No one fails students... it is all hidden. Student goes to drop the examiner at the train station to pass on an envelop. I have never taken that envelop. I have heard 5000 rupees is minimum per student for BSC and GNM... Everyone wants to be an examiner for private institute, for that extra income and no one wants to go to government institutes cause government students wont pay to pass." (Rajasthan)

Corruption is the underlying reason for such malpractice which is kept in place by promoting nurses who are party to it.

"When nurses raise their voice, government removes them from their position. They are not scared of us as we don't have any power. We are dominated from above. We know everything but can do nothing" (Rajasthan)

A participant from Madhya Pradesh commented on the issue of student's non-attendance. Instead of sitting through the classes, students work in smaller nursing homes as assistants for an extra income. These training centres are usually affiliated to big private hospitals, so in terms of requirement, their 'papers' are always complete which means the non attendance goes undocumented. Even though these nursing institutes undergo inspections from the SNC, INC and the state government, they often don't face any regulatory action. Figure 1 shows the current responsibilities of state and central council, along with the overlap in their role and the gaps in regulatory functions.

Figure 1: INC and SNC's role and gaps in regulation of nursing \& midwifery in India (authors own)

\subsection{Gender and power influencing midwifery and nursing regulation}

The states face some unique gender-based challenges. In a female dominated profession, the leadership is male dominated in India and Rajasthan. In Rajasthan, the curriculum is regulated under the leadership of a male Nursing Registrar and practical experience is overseen by a male nursing administrator from the health ministry. Rajasthan and Madhya Pradesh are amongst the few states that allow male students to take up nursing and midwifery education. Although, Rajasthan historically had both men and women candidates in diploma and degree level courses, due to lesser girls opting to do nursing owing to stigma, the inability to ensure the required practical experience in midwifery for male candidates has been a persistent challenge. In some institutions the midwifery professor or clinical instructor is a man, yet there is a strong possibility that he has never assisted a single birth. The issue of the lack of practical midwifery education for male candidates has not been addressed. A participant from Rajasthan, who teaches midwifery, raised this issue faced during his own training.

"I asked them why are you giving us this training when you won't let us practice during the training. What is the point of doing this training?... They (regulatory bodies) are not even thinking in those lines." (Rajasthan)

The INC recommends for students to assist 25 births each in BSc Nursing and MSc Nursing in Obstetrics. A male participant who teaches midwifery assisted only five births including during his BSc in Nursing and Masters in Obstetrics degrees, even though 650 hours of study is required in total for an MSc. Even getting a chance to assist those five births was fraught with difficulties involving persistent efforts to win the trust of the labour room's team of care providers.

Page $8 / 16$ 
"There is stigma for men to work in labour room. Families don't encourage it, so the scope is less." (Rajasthan)

"This gender related problem has existed for over 30 years but INC is not doing anything to address it... the state nursing councils can not do anything about this. Now INC is implementing an 18 months course in midwifery but not looking into the challenges of men in midwifery... INC needs to take a stand... States can not do anything. INC tells, we do. State council can write to INC, but they don't care about the quality of education of nurses and midwives". (Madhya Pradesh)

The nursing and midwifery leaders representing education, administration and service provision brought up similar issues regarding male students lacking practical midwifery exposure. However, the participants representing regulatory bodies shared no such concerns. West Bengal has recently started enrolling male candidates for nursing and midwifery education. The issue of gender is not just about getting a chance to practice midwifery. A participant mentioned that the apparent gender imbalance in the profession is also a reason for the lack of leadership for women in nursing and midwifery.

"People in West Bengal used to think men in nursing won't be accepted by society, but that was a myth. There are two colleges with 50 seats each for male candidates who are also learning midwifery. The $1^{\text {st }}$ batch training is on and it is very exciting." (West Bengal)

The role of doctors, who are usually men, is explored in different ways. They are held responsible for the lack of female representation and growth of the profession. There is frustration about doctors holding key positions in nursing councils.

"Nursing association wants the nursing directorate to be separate so their demands can be addressed. Any demand from a nursing or midwifery association is usually shelved when a doctor policy-maker comes in the picture." (Rajasthan)

"The president of Bihar Nursing Council is a Doctor...there is a lot of politics in all of this. There is pressure from the (Health) Secretary as well." (Bihar)

An interesting rationale came from a participant in West Bengal on the lack of leadership quality in nurse-midwives. According to her, the issue is that "lesser doctors are falling in love with nurses" as more women are being trained as doctors. Given that more recently male doctors are getting married to female doctors, nurses seem to be falling further down in the hierarchy of healthcare. The position of nurses, therefore, diminishes in society because doctors do not consider them their equal anymore. The involvement of men in nursing is deemed to uplift of the image of nursing in the country to reduce the gender based stigma.

"As women, we are ruled by our father, brother, husband and son at different stages of our life... It is our lack of confidence and attitude that only if men are there will we succeed. There is a dependence... we surrender too easily." (West Bengal)

\subsection{Midwifery under nursing as a regulatory challenge}

Participants were asked about their opinion on the midwives current role in India, which is not a direct entry training and is usually practiced on rotation with other nursing roles. Direct entry midwifery is a 3 years degree course recommended by ICM that provides a license of Registered Midwife (RM). Participants responded with mixed opinions on the requirement and future of midwifery in India as an independent profession. While most participants seemed to be in favour of independent midwifery, there were limited and unclear responses on the regulatory challenges it entails. A respondent from Odisha could relate to working independently in the periphery and yet working harder, as the best phase of her career.

"ANM is our independent midwifery practitioner who is assisting deliveries in rural areas as good as doctors are doing independently in the urban areas. Some

ANM'sconductdeliveriesmuchbetterthandoctorsandareveryfamousfortheirwork,peoplespeciallyrequestthemtoassistwiththeirdelivery. " (Rajasthan)

Medical domination for independent midwifery practice is reported as a key barrier as the respondent mentioned "we can not work independently in the tertiary level as the (medical) professors are there" or that "we can not work without their permission". Multiple respondents mentioned not being 'allowed' to do much as a key issue in the tertiary level of care though they have been entrusted with larger responsibilities at the primary and secondary level.

Page 9/16 
"I have done spinal anaesthesia, caesarean section and abortion, under supervision. If a policy is made that we can work independently, it will be uplifting for the profession (of midwifery)." (Odisha)

"Independent midwifery is key to address the situation with disrespect and abuse during childbirth everywhere." (Bihar)

"Nurse and midwife should be separate cadres, like medicine. Rotation is not helping" (National)

Another participant mentioned the lack of a legal framework as a key challenge for independent midwifery in India. This is due to a lack of legal protection for midwifery practitioners, unlike the case with doctors. At the national level, participants felt that the INC should take charge of regulating nursing and midwifery services. Participants have reported these challenges from every state.

"If the INC is the (only) regulatory body (in the country) then that should look after practice. In the 10 years that I have been superintendent, no one has come to check the competency level of my nurses". (National)

" Nothing is happening in terms of nursing regulation. There is no regulation of service." (Bihar)

There are challenges of underfunding as well, which were identified by a participant from Switzerland.

"All of them are badly underfunded. INC has managed to get some funds but given the size of India, its peanuts. It would be effective if they had many more resources. They could really meet, coordinate, re-educate, train, get the evidence and really understand what's going on. Its sad that what's all happening at states is registering and re-registering." (Switzerland)

Respondents felt that the councils should work in favour of midwifery and protect midwives right to practice in an independent profession. The need for a midwifery Act was mentioned a few times, which could encompass the unique challenges that midwives face. A participant stated that a Nursing and Midwifery Practice Act of India is being drafted without any assurance of when it will be enacted. Meanwhile another participant commented that the lack of a midwifery model of care is due to the vested interests of national leaders "... they do not want independent midwifery in India". The independent status of midwifery is expected to bring in more recognition and a boost in salary as is seen in many other countries. A participant from the United Kingdom suggested a way forward,

"I think it would change the status if the public sees that this is a midwife, this is her level of skills. Someone who practices independently, not dependent on doctor. Its straightforward. It automatically shifts the status of the profession. It is fundamental to have that independent status. I know its not easy to organize and make happen. But it's the way forward... Changes in policies will of course support the midwives but also part of what's needed is to get midwifery leaders in the profession who sit there at those tables. There are policies being made about midwifery and maternity care without them at the table. We have got to get ourselves at those top tables... There is strong evidence on midwifery with the lancet series. Its doesn't happen overnight." (United Kingdom)

\section{Discussion}

The ICM identifies Education, Regulation and Association (ERA) as the three pillars for development and practice of midwifery ${ }^{[26]}$. The nursing and midwifery workforce in India faces many challenges in each of these three areas. These three pillars often do not work together for the development of nursing and midwifery in India. The challenges include poor quality of education stemming from a weak regulatory structure that needs to adapt to changes over time. The lack of leadership role and decision-making power for nurse-midwives' further weakens the governance of these professions dominated by doctors $[6,17,36]$. This is a recommendation shared by the majority of participants.

India does not have an independent midwifery workforce or direct entry midwifery education yet. Hence, regulation is currently targeted at nurses who are playing a dual role of nurse and midwife. As more evidence is generated on the advantages of midwifery for maternal and neonatal health [26], it becomes important for the Council to make legitimate efforts to start direct entry midwifery education that will create a cadre of midwives independent of their nursing role. The INC's role will be fundamental in formulating the regulatory structure. This needs to be supported by the respective SNCs in generating evidence and ensuring that culturally appropriate changes are made. This could be done as an addition to the existing INC and the SNCs, or by creating a separate midwifery council with a new midwifery act. 
The Acts in the five states and the INC Act have not been amended for decades, some since independence and before that. A study reviewed the content of the INC act against 21 elements recommended in the International Council of Nursing's (ICN) global standards and found that it addresses only 15 of the stated elements. An amendment of the Act should the elements under all general, structural, functional elements. The current Act is mainly educational which lacks many functional elements such as continuing training required, under education and training; code or standards or conduct/ ethics, disciplinary procedures under fitness to practice; established process under appeals; offences/ penalties listed under offences; and funding of council [27]. The Acts also need to include key definitions such as nurse, nursing, midwife, midwifery, scope of practice and specific scope of practice [27]. This was not an issue identified by the respondents. Interviewing leaders from different aspects of nursing and midwifery governance helped identify many other challenges. The increasing workload was frequently mentioned by the participants representing regulatory bodies which is a challenge reported in other countries as well ${ }^{[28]}$. The participants did not mention genderbased discrimination in education, partial treatment of medical students in comparison to nursing and midwifery students and the powerlessness in nursing, midwifery and health policy making. The doctor dominance and political nature of regulation was reported with caution. All these challenges and more, including lack of leadership qualities in the regulatory bodies, were raised by nursing and midwifery leaders representing education, service provision, association and administration. Respondents urged the need for more transparency and inclusivity in the processes of INC and SNCs. This is essential to ensure accountability ${ }^{[1,17]}$. The participants felt that a change in leadership at INC might improve regulation and that the key position should not be stagnant.

The regulation of private education is particularly concerning, given $88 \%$ of India's nursing education is being imparted in the private sector ${ }^{[6]}$. This creates more avenues for corruption ${ }^{[17]}$. Other issues including non-attendance of students, working in the nursing homes during pre-service education, lack of qualified teachers, less opportunities to practice and illegally practicing with no formal qualification have been reported, which should be addressed by regulatory bodies.

These interviews and evidence reported elsewhere reinforce the urgent need to improve midwifery and nursing education [26,29,37-38]. In the Indian context, shortcomings in regulation have persisted for decades ${ }^{[6,13-16]}$. The participants of this study have clearly identified that key stakeholders have failed to take a gender sensitive approach. Nursing and midwifery needs a more people centric approach to address the existing gender-related barriers. Gender-based discrimination begins with each nursing and midwifery student's education and extends to their clinical practice or teaching thereafter. When male candidates are given opportunities for graduation and post-graduation in midwifery (gynaecology and obstetrics) and all streams of nursing, the SNCs must ensure that they receive enough practical experience ${ }^{[13-15]}$. This could also enable practical experience for all students regardless of their gender. Men and women in the profession have specific issues that need to be addressed in a way that ensures quality education, opportunities to practice and provide care in line with patients rights and choices. Nursing and midwifery being traditionally women dominated professions, adds to the gender based discrimination and stigma they face, which gets exacerbated because of facts such as that of nurse-midwives often coming from poor socio economic background and belonging to backward classes and castes, which has a relevant history behind it on how nursing began and progressed in India ${ }^{[8-9,30]}$. Though it is established that these characteristics has an impact on nurses and midwives education and practice but the extent of it along side the practice of medicine, owing to this intersectionality, remains to be understood in the context of India ${ }^{[31]}$.

A key challenge is the discrimination between nursing-midwifery and medical students, as they practice in the same health care delivery system. This discrimination results in inadequate practical experience opportunities for nursing and midwifery students and establishes a hierarchy in the medical care system early on from pre-service education. This clearly implies the lack of attention given to nursing and midwifery education in comparison with medical education. This hierarchy is often gender-based and creates inequalities within the health care team by centralising decision-making power in the hands of the medical profession at every level of care provision [32]. The powerlessness of nursing and midwifery leaders in health systems policy making, due to the doctor-centric nature of health policy making and regulation, has been a persistent challenge ${ }^{[6,17]}$.

The nursing councils do not play a role in regulation of practice, which is mainly managed by the state and central government bodies. Increasing the SNC's role in practice regulation will ensure quality and evidence-based nursing and midwifery care provision, which could be supervised by the INC to ensure uniformity [1]. Regulation is divided between different bodies including INC, the SNCs, the directorates of medical education and universities. This segregated nature of regulation adds to the confusion and decreases the rigour when education and regulation is managed by so many different bodies, mostly without the involvement of nursing and 
midwifery representatives. It results in duplication of functions such as inspection; while other functions including the regulation of practice are completely ignored.

Literature suggests poor working condition and low remuneration as key drivers for nurses migration from India, which could be addressed by better regulation of practice. Nurse (midwife) migration is also an area that needs to be regulated, given India is a major supplier of nurses to the Middle-East and high-income countries, ranking second in outmigration after Philippines ${ }^{[6,11,33,34]}$. Information about overseas migration and practice on return is provided in other country Acts ${ }^{[28,35]}$. An understanding of the magnitude and reasons for nurse-migration will help to improve the quality of working conditions in India and decrease the workforce shortages by retaining more nurse-midwives.

The respondents interviewed in Switzerland and United Kingdom presented a global perception mentioning some key challenges that were otherwise missed. The lack of evidence-based education was mentioned by a global leader who felt the INC had a role to lead by showing best examples and guiding evidence-based education and practice in the country. The global leaders interviews also highlighted the issue of underfunding for nursing and midwifery, from education to practice, and the development of professions and the professionals within it.

Figure 2 summarises areas and actions for reform midwifery and nursing education and practice regulation in the India along with need for research in future. It presents overarching areas of reform such as governance where the establishment of midwifery and nursing directorate will aid many of the reforms suggested in the other areas of midwifery and nursing in the figure, within which more areas are education, practice, gender and council. Four key reforms measures are suggested for each of the areas. There are some aspects which need more research and understanding in India, which also have been shown in Figure 2, such as, gender-based challenges in nursing, midwifery and health policy making; challenges in private sector education, regulation and practice; scope for independent midwifery practice; development of a strong regulatory structure and implementation of innovative strategies in regulation to ensure good quality and respectful care provision.

\section{Figure 2: Regulatory reforms in midwifery \& nursing education \& practice in India (authors own)}

\section{Conclusion}

Nurses-midwives are the primary health care providers in India. Regulatory failures leads to nurses and midwives graduating without sufficient knowledge and skills thereby putting people's life at risk. This is a serious issue because practice is unregulated, care providers are unsupervised and not updated timely as the standards of care gradually deteriorate. The health regulatory structures of the country, that includes the regulatory bodies of all health care related professions have a major role to play in maintaining standards of education and practice to ensure good quality of health care to its people. This requires a team approach similar to how a team of care providers with different expertise come together to provide quality health services. The INC, the SNCs, the Indian Medical Association (IMA), the directorates of medical education, public and private universities, nursing and midwifery associations and development organizations have a stake in health care regulation. The entities need to come together to understand the issues and work to address those challenges by creating a strong regulatory structure guided by midwifery and nursing leadership.

\section{Abbreviations}

ANM- Auxiliary Nurse Midwife

ANMTC- Auxiliary Nurse Midwifery Training Centre

GNM- General Nursing and Midwifery

GNMTC- General Nursing and Midwifery Training Centre

GOI- Government of India

$\mathrm{HRH}$ - Human Resources for Health

ICM- International Confederation of Midwives

Page 12/16 
ICN-International Council of Nurses

INC- Indian Nursing Council

NHM-National Health Mission

NPM-Nurse Practitioner in Midwifery

NRTS-National Registration Tracking System

PSE-Pre Service Education

SNC-State Nursing Council

WHO- World Health Organization

\section{Declarations}

\section{Ethics Approval and Consent to participate}

The study obtained formal ethical clearance from the Research Ethics Review Board of the Authors' institution (Reference No: 41164) prior to the start of the research. Respondents provided written consent to participate in the study. All respondents were provided with a participant's information sheet with details about the research study. The interviews were audio recorded with consent. To ensure confidentiality, study respondents were anonymised throughout the analysis and presentation of results.

\section{Consent to publication}

Not required.

\section{Availability of data and material}

The data collected and analysed for this study are available from the corresponding author on reasonable request.

\section{Competing interests}

None declared.

\section{Funding}

This study was funded by The Royal Norwegian Embassy in New Delhi under their Norway India Partnership Initiative's (NIPI) Scientific Research Project IND-16/0008.

\section{Authors contributions}

KM conceived the study and its design, collected the data and performed the data analysis and drafted the manuscript. SB and ZM reviewed the design and edited versions of the manuscript. All the authors have read and approved the final manuscript.

\section{Acknowledgements}

We wish to express our appreciation to the midwifery and nursing leaders who have participated in this study.

\section{References}

1. International Confederation of Midwives. 2011. Global standards for midwifery regulation. Regulation.

2. Sheikh K, Raman VR, Mayra K, 2012. Nursing governance in Low and Middle Income Countries (LMICs): Literature Review. Public Health Foundation of India. 
3. Sharma B, Johansson E, Prakasamma M, Mavalankar D, Christensson K. Midwifery scope of practice among staff nurses: A grounded theory study in Gujarat, India. Midwifery. 2013; 29. p. 628-636.

4. Government of India. Guidelines on midwifery services in India. 2018.

5. The State of the World's Midwifery. 2014

6. Rao M, Rao KD, Kumar A, Chatterjee M, Sundararaman T. Human resources for health in India. The Lancet. $2011 ; 377$.

7. Reynolds J., Wisaijohn T., Pudpong N., et al. A literature review: the role of the private sector in the production of nurses in India, Kenya, South Africa and Thailand. Human Resources for Health. 2013; 11:14.

8. Mayra K. Docsplanation: A malady of the healthcare profession. Economic and Political Weekly. 2020a;55:10.

9. Mayra K,. A starched cotton fluorescent yellow saree, khopa, belly button and safety pins: Decoding the dignified Indian nursemidwife. The Practicing Midwife Journal. 2020b; 23:6.

10. Tiwari RR, SharmaK, ZodpeySP. Situational analysis of nursing education and work force in India. Nursing Outlook. 2013; p. 129-136.

11. Khaliq AA, Broyles RW, Mwachofi AK. Global nurse migration: Its impact on developing countries and prospects for future. World Health and Population. 2008;10:3.

12. Public Health Foundation of India. 2011. High level expert group report on Universal Health Coverage for India. Planning Commission of India.

13. ANSWERS, NHSRC., 2009. Nursing services in Bihar. Available at: http://nhsrcindia.org/sites/default/files/Bihar.pdf

14. ANSWERS, NHSRC., 2009. Nursing services in Orissa. Available at: http://nhsrcindia.org/sites/default/files/Orissa.pdf

15. ANSWERS, NHSRC., 2009. Nursing services in Rajasthan. Available at: http://nhsrcindia.org/sites/default/files/Rajasthan.pdf

16. Sharma B, Mavalankar DV, Kulkarni A, et al. Role of nursing councils in regulating nursing and midwifery education, training and practice in India. Midwifery and maternal health in India: Situation analysis and lessons from the field. p. 14-30.

17. Putturaj M, Prashanth NS. Enhancing the autonomy of Indian nurses. Indian Journal of Medical Ethics. 2017; 2:4.

18. Nair S, Rajan S I. Nursing education in India: Changing facets and emerging trends. Economic and Political Weekly. 2017; 52: 24.

19. Government of India. 2015. DAKSHATA: Empowering providers for improved MNH care during institutional deliveries.

20. Indian Nursing Council. 1947. The Indian Nursing Council Act. Act 48 of 1947.

21. Government of Bengal. 1934. The Bengal Nurses Act. Act X of 934.

22. The Bihar and Orissa Nurses Registration Act 1935. Act 1 of 1935.

23. Government of the central provinces and bear medical department. 1941. The Central Provinces Nurses Registration Act. (XXIII of 1941).

24. Authority of the Orissa Nurses and Midwives Council. 1940. Manual of the Orissa nurses and midwives' council.

25. Rajasthan Nurses, Midwives, Health Visitors and Auxiliary Nurse-Midwives Registration Act. 1964.

26. Lopes CL, Nove A, Hoope-Bender P, et al. A descriptive analysis of midwifery education, regulation and association in 73 countries: the baseline for a post 2015 pathway. Human Resources for Health. 2016;14:37.

27. Elison NK, Verani AR, McCarthy C. National nursing and midwifery legislation in countries of South-East Asia with high HIV burdens. WHO South East Asia Journal of Public Health. 2015; 4:102. p-12-19.

28. McCarthy CF, Voss J, Salmon M, E, Gross MJ, Kelly AM, Riley LP. Nursing and midwifery regulatory reform in east, central and southern Africa: a survey of key stakeholders. Human Resources for Health. 2013; 11: 29.

29. , NHSRC., 2017. Nursing policies, reforms, and governance structures. Analysis across five states in India.

30. Ray P. Care (Un)skilled: fragmented markets and nursing labour, contemporary Kolkata. Land, Labour and Livelihoods: Indian women's perspectives. Ed. Fernandez B, Gopal M, Ruthven 0. 2016. p. 239-260.

31. Cehat, AMCHSS. Gender in medical education. 2002.

32. Philby A, McConville F, Portella A. What prevents quality midwifery care? A systematic mapping or barriers in Low and Middle Income Countries from the provider perspective. PloS One. 2016;11:5.

33. Khadria B. International nurse recruitment in India. Health research and educational trust. 2007; 42:3.

Page $14 / 16$ 
34. Wells M. The experiences of Indian nurses in America. PhD Dissertation. Seton Hall University. 2013.

35. Health Professions Regulatory Act, 2013. Ghana Nursing and Midwifery Council (Part III). pp 28-37.

36. Boylan J, Dacre J, Gordon H. Addressing women's under-representation in medical leadership. The Lancet. 2019;393.

37. Raman SP, Mavalankar DV, Kulkarni A, Upadhyay M, Deodhar A. Historical perspective of nursing and midwifery: training, education and practice in India. In: Visaria L. editor. Midwifery and maternal health in India: Situation analysis and lessons from the field. Indian Institute of Management; 2010.

38. Sharma B, Hildingsson I, Johansson E, Prakasamma M, Ramani K V, Christensson K. Do the pre service education programmes for midwives in India prepare confident 'registered midwives'? A survey from India. Global Health Action. 2015; 8.

\section{Figures}

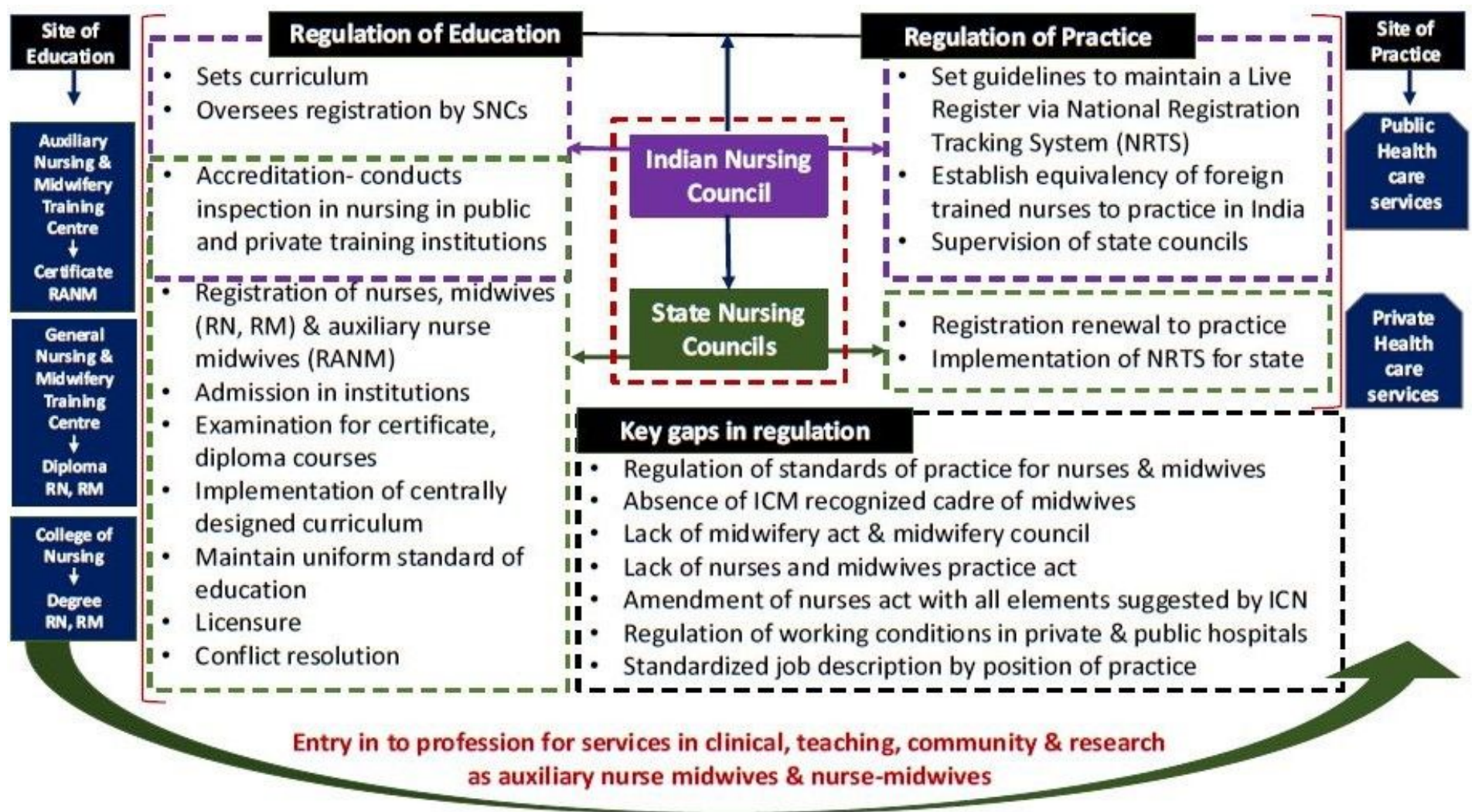

Figure 1

INC and SNC's role and gaps in regulation of nursing \& midwifery in India (authors own) 


\begin{tabular}{|c|c|c|c|c|}
\hline Governance & \multicolumn{4}{|c|}{ Establishment of DIRECTORATE OF MIDWIFERY AND NURSING under Government of India } \\
\hline Midwifery & \multicolumn{4}{|c|}{$\begin{array}{l}\text { Establishment of Midwifery Council of India and State Midwifery Councils } \\
\text { Enactment of Midwifery Act of India and State Midwifery Acts }\end{array}$} \\
\hline Nursing & \multicolumn{4}{|c|}{$\begin{array}{l}\text { Amendment of Indian Nurses Act of } 1947 \\
\text { Regulation of nurses practice in public and private sector }\end{array}$} \\
\hline Education & 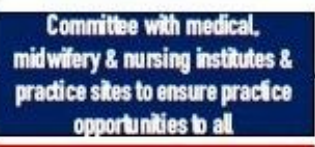 & $\begin{array}{l}\text { Measires to address } \\
\text { comupfionin admission } 8 \\
\text { examination }\end{array}$ & $\begin{array}{l}\text { Strenghen mechanisms to } \\
\text { reduce gaps in theory \& } \\
\text { practice }\end{array}$ & $\begin{array}{l}\text { Informalion on educetional } \\
\text { seats \& instutes by public } \\
\text { and private h council } \\
\text { wethites. }\end{array}$ \\
\hline Practice & $\begin{array}{l}\text { Measures b adtress the issue of } \\
\text { practicing with fake cerficates }\end{array}$ & $\begin{array}{l}\text { Job descipition for every } \\
\text { posilion in he carcer } \\
\text { pathway of nurse-mithives }\end{array}$ & $\begin{array}{c}\text { Standards for woiking } \\
\text { condtions for nurses \& } \\
\text { midtwives }\end{array}$ & $\begin{array}{l}\text { Regilab he student and case } \\
\text { loed rafio at the affilited } \\
\text { hosplats }\end{array}$ \\
\hline Gender & $\begin{array}{l}\text { Admission to the courses of } \\
\text { certificate, diploma \& degree } \\
\text { courses of mitwifery \& nursing to } \\
\text { everyone regardless of gender }\end{array}$ & $\begin{array}{l}\text { Gender neutral. respectilil } \\
\text { mursing \& mitwifiery } \\
\text { education \& language in } \\
\text { curriculums \& Adts }\end{array}$ & $\begin{array}{l}\text { Add a curse on gender in } \\
\text { all the curriculums of } \\
\text { midwilery \& nursing }\end{array}$ & $\begin{array}{l}\text { Commiltees in insthutions b } \\
\text { didtress sexual harassment \& } \\
\text { gender based discrimination }\end{array}$ \\
\hline Councils & $\begin{array}{l}\text { Incresse human resurces and } \\
\text { other resources at the coun dils }\end{array}$ & $\begin{array}{l}\text { Increase imestment } 8 \\
\text { funding for he regulatory } \\
\text { bodies }\end{array}$ & $\begin{array}{l}\text { Timely change in leaderstip } \\
\text { a the councils based on } \\
\text { merit \& capability }\end{array}$ & $\begin{array}{l}\text { A mechanism of supervision } \\
\& \text { accountabitly between the } \\
\text { councils }\end{array}$ \\
\hline $\begin{array}{l}\text { Research \& } \\
\text { development }\end{array}$ & \multicolumn{4}{|c|}{$\begin{array}{l}\text { RESEARCH NEEDS: } \\
\text { Analysis of the GENDER based discrimin ation in midwifery and nursing education and practice } \\
\text { Situation analysis of education \& practice in the PRIVATE sector } \\
\text { Nursing \& midwifery WORKFORCE NEEDS ANALYSIS for health care provision: availability+ policies } \\
\text { - Analysis of investment to nursing \& midwifery education and regulation } \\
\text { Creation of standards for midwifery \& nursing practice } \\
\text { - Required vs current availability of CONTINUED MIDWIFERY \& NURSING EDUCATION } \\
\text { - MIDWIFERY \& NURSING RESEARCH \& ADCOVACY UNIT with councils to ensure evidence based education \& practice }\end{array}$} \\
\hline
\end{tabular}

Figure 2

Regulatory reforms in midwifery \& nursing education \& practice in India (authors own)

\section{Supplementary Files}

This is a list of supplementary files associated with this preprint. Click to download.

- Coverletter.docx 